\title{
Association Between Cathepsin S, Cystatin C and High Sensitivity C-Reactive Protein (hsCRP) with Oxidized LDL (Ox-LDL) in Men with Central Obesity
}

\author{
Emmy F. Harefa ${ }^{1,2 *}$, Ilhamjaya Patellongi ${ }^{3}$, Marita Kaniawati ${ }^{1,2}$ \\ ${ }^{1}$ Prodia Clinical Laboratory, Jl. Cisangkuy No. 2, Bandung, Indonesia \\ ${ }^{2}$ Post Graduate Program in Clinical Biochemistry, Hasanuddin University, Jl. Perintis Kemerdekaan Km. 10, Makassar, Indonesia \\ ${ }^{3}$ Faculty of Medicine, Hasanuddin University, Jl. Perintis Kemerdekaan Km. 10, Makassar, Indonesia \\ *Correspondence: emmy.harefa@prodia.co.id
}

\section{Abstract}

ACKGROUND: Inflammation is a central feature of the atherosclerotic process particularly in obesity. hsCRP, a marker of inflammation, may be directly involved in all phases of atheroslerosis by complement activation, apoptosis, vascular cell activation, monocyte recruitment, lipid accumulation and thrombosis $(1,2)$. Inflammation has a causal relationship with cysteine proteases including cathepsin S. Therefore, cathepsin S is considered as a molecular link between obesity and atherosclerosis (3). An imbalance between elastolytic cysteine proteases, cathepsin $\mathrm{S}$ and its inhibitor, cystatin $\mathrm{C}$, is involved in the pathogenesis of atherosclerosis $(4,5,6)$. Some studies have shown that increased circulating levels of cathepsin S, hsCRP and cystatin C in inflammatory conditions contribute to atherosclerosis. This study was conducted to investigate the associations between ox-LDL and cathepsin S, and cystatin C and hsCRP in men with central obesity.

METHODS: This was a cross-sectional study involving 71 male subjects with central obesity (waist circumference $\geq 90 \mathrm{~cm}$ ), with no renal dysfunction, aged 30-60 years.

RESULTS: Cathepsin S did not have a significant correlation with ox-LDL $(r=0.158, p=0.096)$. Ox-LDL had positive correlation with cystatin $\mathrm{C}(\mathrm{r}=0.156 ; \mathrm{p}=$
$0.029)$ and $h s C R P(r=0.204 ; p=0.045)$, and cathepsin $\mathrm{S} /$ cystatin $\mathrm{C}$ ratios $(\mathrm{r}=0.360 ; \mathrm{p}=0.024)$ at level $>91 \mathrm{U} / \mathrm{L}$ (median ox-LDL).

CONCLUSIONS: There were associations between oxLDL and cystatin C, hsCRP and cathepsin S/cystatin C ratios in men with central obesity.

KEYWORDS: Obesity, inflammation, atherosclerosis, hsCRP, cystatin C, cathepsin S, ox-LDL

Indones Biomed J 2012; 4 (1): 50-57

\section{Introduction}

Atherosclerotic cardiovascular disease (CVD) is a major health problem all over the world including Indonesia. Obesity, one of the primary risk factors for atherosclerosis, has a correlation with morbidity and mortality of cardiovascular diseases (1). However, the exact molecular pathways that underlies these relationships remain to be poorly understood. Evidence has accumulated indicating that obesity is associated with a state of chronic, low-grade inflammation (7). Inflammation triggered by obesity may accelerate the process of atherosclerosis (8). In obesity, the adipose tissue is infiltrated by macrophages and it secretes 
the proinflammatory cytokines (9). The adipose tissue is not only a storage of fat but also an active endocrine organ that secretes various bioactive factors known as adipokines, and it can trigger the inflammatory changes mediated by cytokines in the liver, systemic inflammation and atherosclerosis (9).

Atherosclerosis is characterized by lipid accumulation in large and medium-sized arteries. Lipid accumulation and oxidation are followed by inflammatory response and release of cytokines, which participate in the regulation of protease expression and activation (10). It is mentioned that proteases are involved in regulation of cell migration and plaque stability. The two most studied protease families are serine proteases and matrix metalloproteinases (10). But in the recent years, the cysteine proteases of the cathepsin family have been reported of having an important role in atherosclerotic disease (11). Cystatin $\mathrm{C}$ is a protein present in all nucleated cells and it is secreted into the extracellular space. Cystatin $\mathrm{C}$ functions as an inhibitor of cysteine proteases of the cathepsin family. Protease inhibitors including cystatin $\mathrm{C}$ are generally regarded as atheroprotective or antiatherosclerosis, because the role of proteases in matrix degradation, which constitutes the major atherogenic process (8).

Cathepsin $\mathrm{S}$ is a family of proteolytic enzymes that not only could degrade intracellular proteins engulfed by lysosomes, but also extracellular elements such as elastin, fibronectin, laminin and collagens (12). Degradation of extracellular matrix (ECM) in the vessel wall enables smooth muscle cells (SMCs) to migrate from media into intima and inflammatory cells to infiltrate from circulation into arterial wall, critical process in the pathogenesis of atherosclerosis (13). Cathepsin $\mathrm{S}$ has been suggested as a molecular link between obesity and atherosclerosis, possibly mediated via adipose tissue-derived inflammation (3).

Associated with atherogenic changes, inflammation may be one mechanism that is associated with cystatin $\mathrm{C}$ and cardiovascular risk, and its high cystatin $\mathrm{C}$ concentrations have a correlation with high CRP concentrations (14). It is possible that this association could be associated with the presence of renal dysfunction $(13,15)$, but it has been suggested that high cystatin $\mathrm{C}$ concentrations are directly related to both inflammation and atherosclerosis (15).

There is evidence to indicate that both elastolytic cysteine proteases and their inhibitors, an important one of which is cystatin $\mathrm{C}$, are involved in the pathogenesis of atherosclerosis. Studies have suggested that rather than the circulating levels, the imbalance between proteases and inhibitors determines their net effects on the cardiovascular system $(4,7,16,17)$. Inflammatory cytokines associated with atherosclerosis stimulate the production of lysosomal cathepsins, and increased plasma concentrations of cystatin $\mathrm{C}$, as cathepsin inhibitor, may play a role to counterbalance the potentially damaging increase of elastolytic activity. Researchers have shown that human cathepsins are expressed in smooth muscle cells, endothelial cells, and macrophages, and as such they are involved in the progression, composition, and rupture of atherosclerotic plaques $(15,17)$. Increased concentration of cathepsin promotes a wide spectrum of simultaneous cellular activities, such as ECM degradation, activation of endothelial cells, migration of macrophages, lipid accumulation in vascular wall, particularly exacerbating the evolution of atherosclerotic plaque (17).

Atherosclerosis represents the condition of increased oxidative stress characterized by oxidation of lipid and protein in the vascular wall. The oxidative modification hypothesis assumes that LDL (Low-Density Lipoproteins) oxidation is an early event in atherosclerosis, and that oxLDL is one of the important contributors of atherogenesis (18). Experimental researchers have shown that ox-LDL is directly involved in the initiation and progression of atherosclerotic lesions, from the earliest stages to the late-stage development of plaque instability and rupture $(19,20)$. This study was aimed to investigate the correlation of ox-LDL and cathepsin S with cystatin $\mathrm{C}$ in the condition of inflammation, as represented by the marker hsCRP, in men with central obesity.

\section{Methods}

\section{STUDY DESIGN AND SUBJECTS}

This was a cross-sectional study conducted at the Prodia Clinical Laboratory in Bandung and Jakarta (January 2012-March 2012) involving 71 male subjects with central obesity (waist circumference $\geq 90 \mathrm{~cm}$ ), aged 30 60 years. Central obesity was defined according to the International Diabetes Federation 2005 criteria as waist circumference $\geq 90 \mathrm{~cm}$ for men. All the study subjects did not have chronic kidney disease [Estimated GFR (eGFR) using Modification of Diet in Renal Disease (MDRD) $>60 \mathrm{~mL} /$ minute)], abnormal liver function test (serum glutamic oxaloacetic transaminase (SGOT)/serum glutamate pyruvate transaminase $($ SGPT) $>2 \mathrm{~N}$ ), thyroid disorder (thyroid stimulating hormone/TSH $>4.94 \mathrm{uIU} /$ $\mathrm{mL}$ for hypothyroid and $\mathrm{TSH}<0,35 \mathrm{uIU} / \mathrm{mL}$ ) or acute inflammation (hsCRP $<10 \mathrm{mg} / \mathrm{L}$ ). The study protocols were approved with the ethical clearance from the 
Health Research Ethics Committee, Faculty of Medicine, Hasanuddin University, Makassar (no.UH12010014). All subjects gave a written informed consent. During the baseline examination, each subject completed a self administered questionnaire covering medical history, exercise, medicine intake for any inflammatory history, smoking habits, and alcohol intake. The questionnaires for screening were checked by the principal researcher.

All subjects were examined after an overnight fasting for 10-12 hours. Measurements were done to assess anthropometric parameters (waist circumference $\geq 90 \mathrm{~cm}$, height, weight, blood pressure) and several biochemical variables (concentration of fasting glucose, HDL-Cholesterol, triglyceride, creatinine, SGOT, SGPT, total cholesterol, LDL-C, TSHs, hsCRP, cystatin C, cathepsin $\mathrm{S}$ and ox-LDL). Fasting serum samples were obtained and kept at $-20^{\circ} \mathrm{C}$.

\section{ASSAY OF BIOCHEMICAL MARKERS}

Creatinine (mg/dL), HDL-Cholesterol (mg/dL), total cholesterol $(\mathrm{mg} / \mathrm{dL})$, LDL-Cholesterol $(\mathrm{mg} / \mathrm{dL})$, triglyceride $(\mathrm{mg} / \mathrm{dL})$, fasting plasma glucose (mg/dL), SGOT (U/L), SGPT(U/L) were determined using Prodia Clinical Laboratory routine procedures by Modular P800 (Roche). TSHs (uIU/mL) levels were evaluated using an Abbott Architect 2000 device and the Chemiluminescence Microparticle Immunoassay (CMIA) method.

Serum concentration of hsCRP $(\mathrm{mg} / \mathrm{L})$ was measured by immunochemiluminescent assay of Immulite 2000 (Diagnostic Products Corporation). Cystatin C (mg/L) was measured by particle-enhanced immunonephelometry by Siemens in Behring Nephelometer Prospec device. Plasma Ox-LDL (U/L) was measured using a mouse sandwich ELISA from Mercodia (Mercodia oxidized LDL ELISA). Cathepsin $\mathrm{S}(\mathrm{pg} / \mathrm{mL})$ was determined by ELISA method from Adipobiotech.

\section{STATISTICAL ANALYSIS}

Statistical analysis were performed with SPSS for Windows version 13.0 software (SPSS Inc., Chicago, IL, USA). Distributions of continous variables were assessed for normality using the Kolmogorov-Smirnov test. Correlations between variables were analyzed using Pearson, Spearman and Kendall's Tau correlation analyses. The results are narrated and explained in tables and graphs. For the statistical tests we used $5 \%$ as the level of significance.

\section{Results}

The early or screening stages of this study were participated by 90 adult males, 30-60 years of age. Anamnesis and physical examination were carried out to assess the waist circumference (WC), blood pressure, weight and height of the study subjects. Four men with WC less than $90 \mathrm{~cm}$ were excluded. Blood tests were done to evaluate SGOT, SGPT, fasting blood glucose, total cholesterol, HDL cholesterol, LDL cholesterol, triglycerides, creatinine, hsCRP and TSHs. Based on the laboratory results, 19 participants were excluded ( 4 of SGPT/SGOT $>2 \mathrm{~N}, 5$ subjects with hsCRP $>$ $10 \mathrm{mg} / \mathrm{dL}, 3$ subjects with $\mathrm{eLFG}<60 \mathrm{~mL} /$ minute $/ 1.73 \mathrm{~m}^{2}$, 1 subjects with TSH $>4.94 \mathrm{uIU} / \mathrm{mL}, 2$ subjects with TSH $<0,35 \mathrm{uIU} / \mathrm{mL}$ ). In addition, we finally decided to exclude another participant from the model, as we considered the subject (single data) as an outlier of Ox-LDL that may cause biases in the subsequent analyses. The clinical and biochemical characteristics of the subjects examined are shown in Table 1.

Pearson or Spearman's correlations test was performed to assess correlations. The result of the correlation test of obesity based on WC showed significant correlation with hsCRP ( $\mathrm{p}=0.035)$ only, but not with Cathepsin $\mathrm{S}(\mathrm{p}=$ $0.610)$, Cystatin C ( $\mathrm{p}=0.066)$ and ox-LDL ( $\mathrm{p}=0.541)$. There was a significant increase in hsCRP concentration at $\mathrm{WC}$ up to $110 \mathrm{~cm}(\mathrm{r}=0.253, \mathrm{p}=0.035)$, but it started to decline at WC above $110 \mathrm{~cm}$ (Figure 1).

In subjects with $\mathrm{WC}<110 \mathrm{~cm}$, the inflammatory factors that worked might be only hsCRP as indicated by the test value $\mathrm{p}<0.05$ and result of WC correlation were only significant with $\mathrm{hsCRP}(\mathrm{r}=0.253, \mathrm{p}=0.035)$. hsCRP is one of the inflammatory markers that is most reliable and accessible for clinical use (21). Serum CRP can detect even a minor level of inflammation (22). CRP may be involved in each phase of atherosclerosis by directly influencing processes like complement activation, apoptosis, vascular cell activation, monocyte recruitment, accumulation of lipid and thrombosis (23). Analysis was then done to see the qubic relationship between hsCRP with each marker of ox-LDL, cystatin C and cathepsin S (Figure 2). OxLDL concentrations appeared to increase significantly after hsCRP concentration reached $8 \mathrm{mg} / \mathrm{L}$ (Figure 2a). The same tendency was shown by cathepsin S (Figure $2 b$ ). When inflammatory condition occurred (in this case indicated by hsCRP), concentration of cathepsin $\mathrm{S}$ tended to increase significantly at hsCRP concentration of $8 \mathrm{mg} / \mathrm{L}$ and alleged that back compensation from cystatin $\mathrm{C}$ as inhibitor of cathepsin S still did not occur or it was still in balance (Figure $2 \mathrm{c}$ ) 
Table 1. Clinical and biochemical characteristics of the study subjects

\begin{tabular}{lcccc}
\hline Variables & Mean \pm SD & Median & Min & Max \\
\hline BMI $\left(\mathrm{kg} / \mathrm{m}^{2}\right)$ & $28.91 \pm 3.08$ & 27.91 & 23.79 & 38.87 \\
SBP $(\mathrm{mmHg})$ & $130.43 \pm 16.55$ & 130.00 & 100 & 190 \\
DBP $(\mathrm{mmHg})$ & $82.86 \pm 6.84$ & 80.00 & 70 & 100 \\
WC $(\mathrm{cm})$ & $97.47 \pm 7.32$ & 95.00 & 90 & 125 \\
Age $($ year $)$ & $43.77 \pm 8.75$ & 41.00 & 30 & 60 \\
GOT $(\mathrm{U} / \mathrm{L})$ & $27.23 \pm 9.71$ & 26.00 & 2 & 66 \\
GPT $(\mathrm{U} / \mathrm{L})$ & $40.03 \pm 19.22$ & 36.50 & 8 & 100 \\
Fasting blood glucose $(\mathrm{mg} / \mathrm{dL})$ & $102.69 \pm 31.18$ & 95.00 & 82 & 289 \\
Total-C $(\mathrm{mg} / \mathrm{dL})$ & $215.07 \pm 41.33$ & 214.50 & 132 & 348 \\
HDL-C $(\mathrm{mg} / \mathrm{dL})$ & $44.46 \pm 8.09$ & 44.00 & 31 & 70 \\
Direct-C $(\mathrm{mg} / \mathrm{dL})$ & $135.86 \pm 35.18$ & 137.00 & 68 & 231 \\
Triglyceride $(\mathrm{mg} / \mathrm{dL})$ & $195.84 \pm 131.91$ & 166.50 & 48 & 847 \\
Creatinine $(\mathrm{mg} / \mathrm{dL})$ & $0.93 \pm 0.12$ & 0.92 & 0.63 & 1.20 \\
eGFR $\left(\mathrm{mL} / \mathrm{mnt} / 1.73 \mathrm{~m}^{2}\right)$ & $91.20 \pm 14.80$ & 90.02 & 64 & 132 \\
TSHs $(\mathrm{ulU} / \mathrm{ml})$ & $1.62 \pm 0.68$ & 1.45 & 0.41 & 3.91 \\
hsCRP $(\mathrm{mg} / \mathrm{L})$ & $1.85 \pm 1.60$ & 1.28 & 0.297 & 8.53 \\
Cystatin C $(\mathrm{mg} / \mathrm{L})$ & $0.85 \pm 0.11$ & 0.84 & 0.64 & 1.18 \\
Cathepsin S $(\mathrm{pg} / \mathrm{mL})$ & $13342.74 \pm 2561.79$ & 13545.40 & 3878.6 & 18040 \\
Ox-LDL $(\mathrm{U} / \mathrm{L})$ & $98.61 \pm 27.76$ & 91.00 & 53 & 189 \\
& & & & \\
\hline
\end{tabular}

$\mathrm{SBP}=$ Systolic Blood Pressure; DBP=Diastolic Blood Pressure; BMI=Body Mass Index; Min=Minimum; Max = Maximum; WC $=$ Waist Circumference.

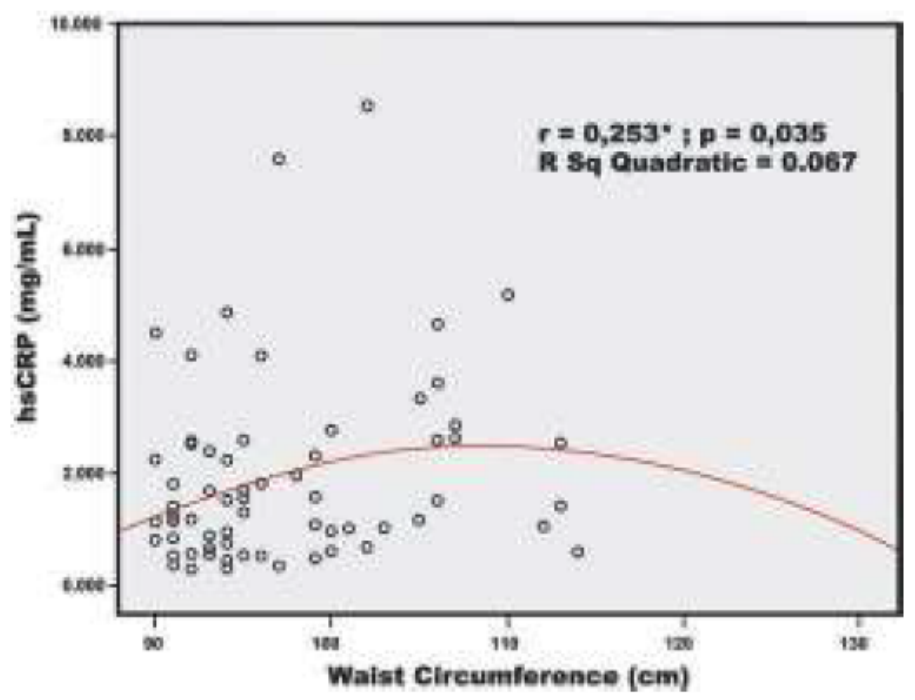

Figure 1. Quadratic Relationship of WC and hsCRP. 


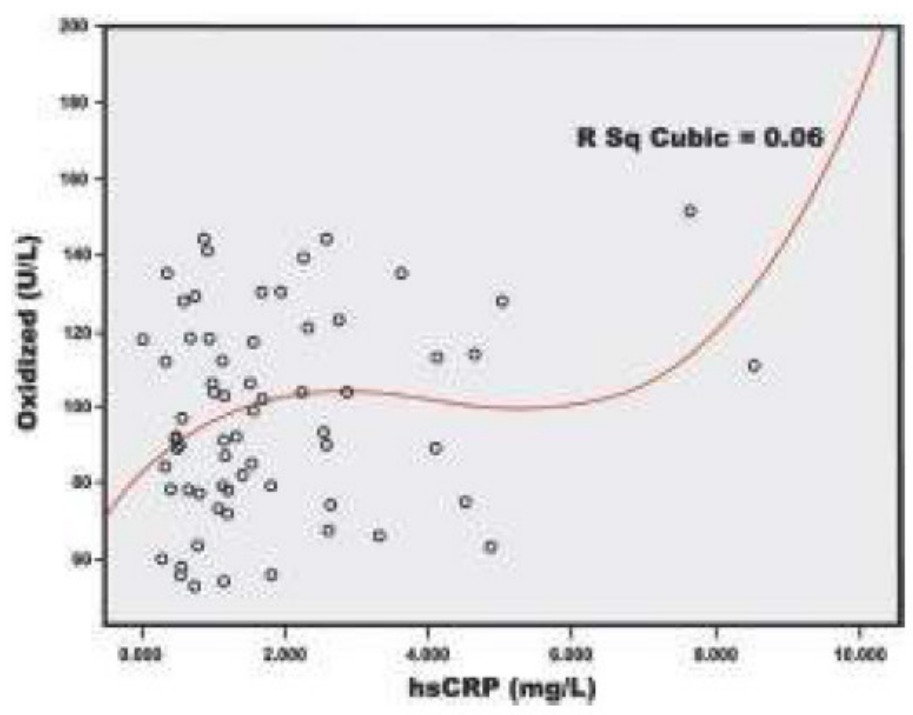

Figure 2a. Cubic relationship between hsCRP and Ox-LDL.

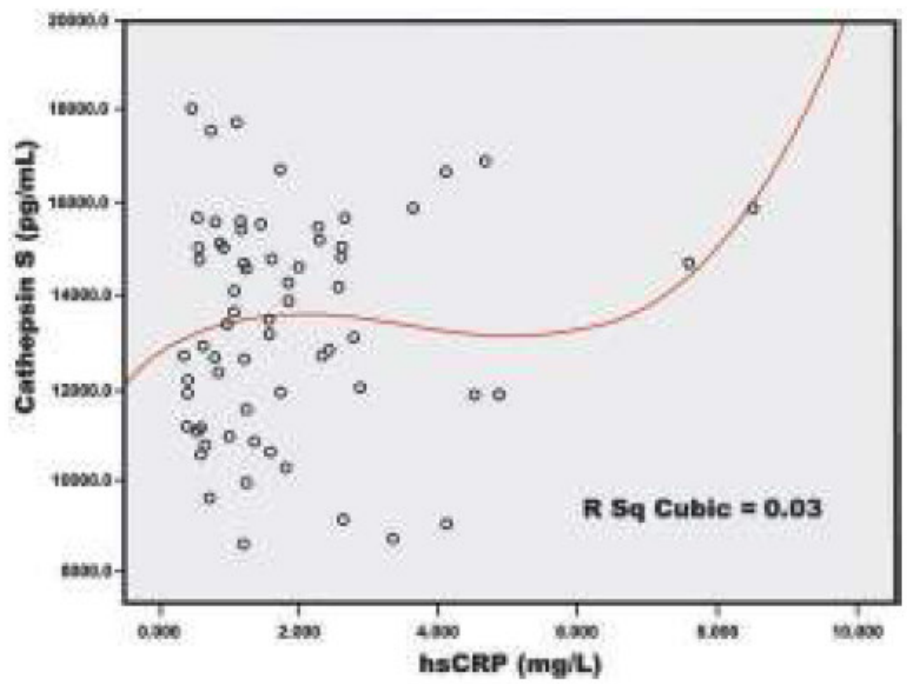

Figure 2b. Cubic relationship between hsCRP and Cathepsin S.

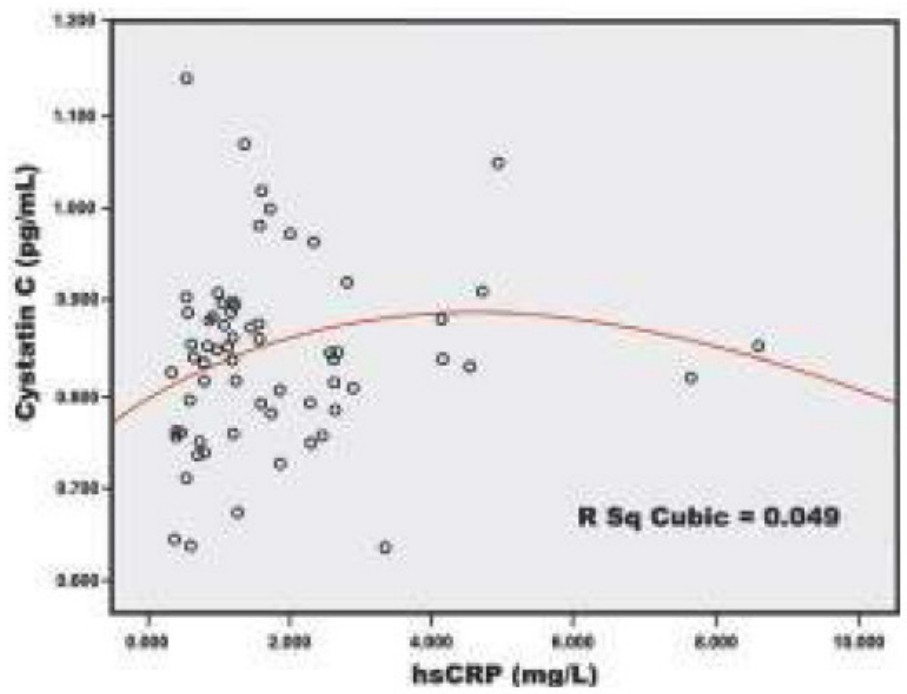

Figure 2c. Cubic relationship between hsCRP and Cystatin C. 
Table 2. Correlation Cathepsin S/Cystatin C ratio with Ox-LDL

\begin{tabular}{|c|c|c|c|c|}
\hline \multirow{3}{*}{ Parameter } & \multicolumn{4}{|c|}{ Ox-LDL $(n=70)$} \\
\hline & \multicolumn{2}{|c|}{$<91$ U/L $(n=35)$} & \multicolumn{2}{|c|}{$\geq 91 \mathrm{U} / \mathrm{L}(\mathrm{n}=35)$} \\
\hline & $\mathbf{r}$ & $\mathbf{p}$ & $\mathbf{r}$ & $\mathbf{p}$ \\
\hline Cathepsin S/Cystatin C ratio & 0.198 & 0.134 & $0.336^{\star}$ & 0.024 \\
\hline
\end{tabular}

${ }^{*}=$ correlation was significant at 0.05 level (1-tailed).

In our study no significant correlation was found between cathepsin $\mathrm{S}$ and $\mathrm{ox}-\mathrm{LDL}(\mathrm{r}=0.172 ; \mathrm{p}=0.082)$. But there was a significant linear correlation between cystatin $\mathrm{C}$ and ox-LDL $(\mathrm{r}=0.156 ; \mathrm{p}=0.029)$. This suggests that cystatin $\mathrm{C}$ may be involved in atherosclerosis process, as we know that the causes of atheroscerosis are multifactorial. The linear correlation between hsCRP and ox-LDL ( $\mathrm{r}=$ $0.204 ; \mathrm{p}=0.045$ ) proved that hsCRP as inflammatory factor contributes to the pathogenesis of atherosclerosis, characterized by increased concentration of ox-LDL in central obesity. Our study showed a significant linear correlation between ratios of cathepsin S/cystatin $\mathrm{C}$ at the concentrations above the median Ox-LDL(91 U/L).

\section{Discussion}

The main finding of our study was the relationship between central obesity and inflammatory condition in the pathogenesis of atherosclerosis as shown by the linear analysis results $(\mathrm{p}<0.05)$, except for the correlation test of cathepsin S with ox-LDL, which showed a positive result but not significant $(\mathrm{p}=0.158)$.

We found a significant correlation between cystatin C and ox-LDL in obese individuals with waist circumference $\geq 90 \mathrm{~cm}(\mathrm{r}=0.156, \mathrm{p}=0.029)$ and the correlation value was greater in obese individuals with waist circumference $>110 \mathrm{~cm}(\mathrm{r}=0.233, \mathrm{p}=0.032)$. This explains the possibility of compensation mechanism from cystatin $\mathrm{C}$ to reduce cathepsin activity so that its concentration decreases, and consequently decrease in cystatin $\mathrm{C}$ concentration induces secretion from endothelial cells, smooth muscle cells (SMCs), and macrophages to release cystatin $\mathrm{C}$ into the circulation. High concentration of cystatin $\mathrm{C}$ is correlated with the expansion of larger atherosclerotic plaque (4). However, the results of the analysis OR 1.714 (95 CI: 0.439 to 6.699 ) in this study did not indicate high cystatin $\mathrm{C}$ as a risk factor for increasing the concentration of Ox-LDL, because data in this study showed that there was still a balance between concentration of Cystatin $\mathrm{C}$ and Cathepsin S.

We found a positive correlation but not significant between cathepsin S and ox-LDL ( $p>0.05$ ). A study has found that higher circulating concentration of cathepsin $\mathrm{S}$ was a consequence of the prevalence of CVD, which could constitute a higher risk of mortality (3). Lack of association in our study was probably due to the small number of samples that had a history of cardiovascular risk ( $8.45 \%$ based on questionnaire data). Another possible interpretation is that cathepsin $\mathrm{S}$ is expressed highly in malignancy tissues (3), but in this study no marker of malignancy was noted to exclude the cause of the high concentration of cathepsin S (maximum 18040.0).

Our study showed a significant linear relationship between cathepsin S/cystatin $\mathrm{C}$ ratios and ox-LDL ( $\mathrm{r}=$ $0,336 ; \mathrm{p}=0.024)$ at a concentration $\geq$ median Ox-LDL (91 U/L), as shown in Figure 3. These results support the explanation that the dynamic balance between cathepsin and cystatin $\mathrm{C}$ affects protein catabolism and different physiological pathways. This effect can cause the onset of various pathological conditions such as cancer and cardiovascular diseases (24). Increased cathepsin S/ cystatin $\mathrm{C}$ ratio may determine the degree of biological effects of cathepsin $\mathrm{S}$ in the pathogenesis of atherosclerosis (25).

Our study showed that hsCRP correlated significantly with WC $(p=0.035)$ and IMT $(p=0.029)$. This indicates that obesity is a systemic inflammatory condition characterized by increased hsCRP as acute phase protein . This significant relationship may be partly mediated by adipose tissue, a major source of proinflammatory cytokines.

hsCRP has a significant correlation with ox-LDL $(r=$ $0.204, p=0.045$ ). This result proved that inflammatory mechanism (in this study represented by hsCRP) plays an important role in all stages of atherosclerosis, 


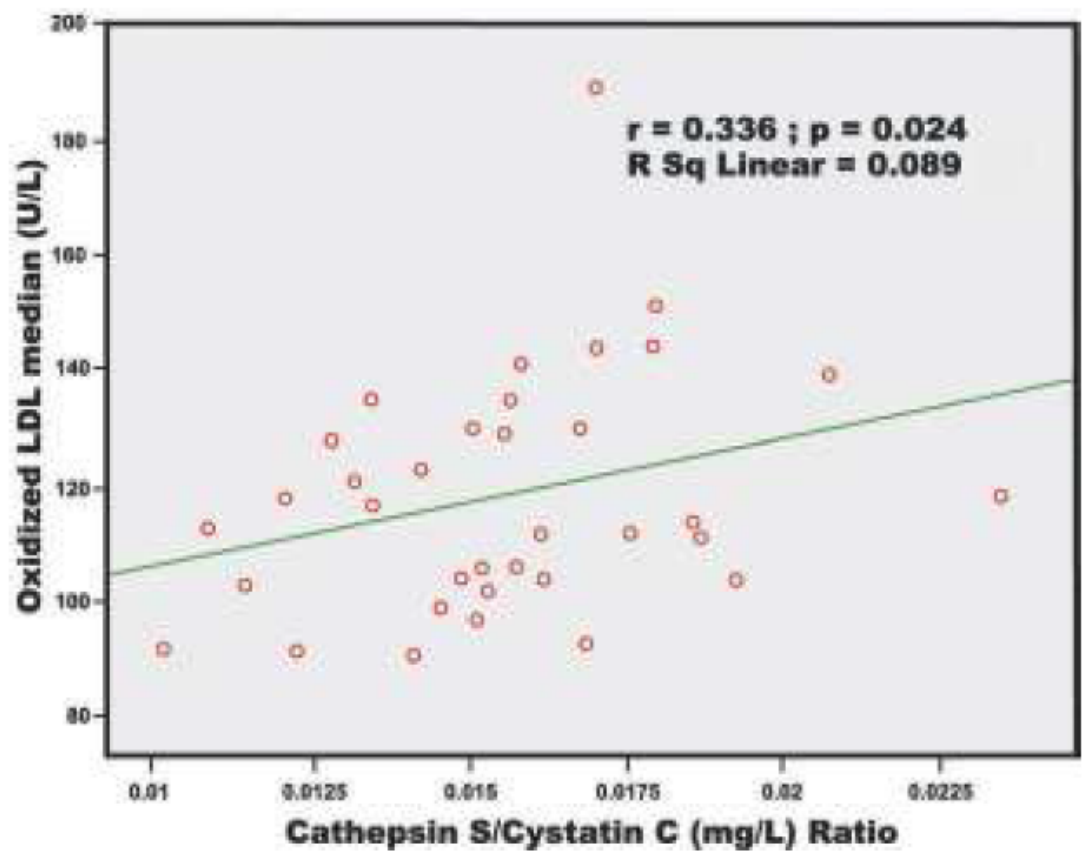

Figure 3. Significant Linear Correlation Ratio Cathepsin S/Cystatin C with OxLDL.

from recruitment of leukocytes in circulation in artery wall to rupture phase of unstable plaque. hsCRP is directly involved in every stage of the complement activation, apoptosis, vascular cell activation, monocyte recruitment, lipid accumulation and thrombosis. hsCRP increases the release of endothelin-1 and upregulation of adhesion molecules and chemokines chemoattractants in endothelial cells and vascular SMCs (26). Lyon et al. also confirmed that the increased expression of adipositokin could trigger inflammation that in turn would lead to insulin resistance and endothelial dysfunction, and further led to atherosclerosis (27). Inflammatory responses are associated with the initiation, growth and complications of atherosclerotic plaque, resulting in increased concentration of hsCRP which leads to inflammation in the artery wall. As such, the CRP can be used as a clinical marker for predicting the risk of cardiovascular disease.

\section{Conclusions}

There were significant correlations between the concentrations of ox-LDL and hsCRP, cystatin C, and cathepsin S/Cystatin C ratio at the level $\geq 91 \mathrm{U} / \mathrm{L}$ (median ox-LDL) in men with central obesity. However, the positive correlation noted between cathepsin $\mathrm{S}$ and oxLDL was not significant.

\section{Acknowledgement:}

We would like to thank the Prodia Education and Research Institute, Research Support Department of Prodia Clinical Laboratory, Prodia Clinical Laboratory - Makassar, and Prodia Clinical Laboratory - Bandung, for their invaluable supports for this study.

\section{References:}

1. Wahba IM, and Mak, RH. Obesity and Obesity-Initiated Metabolic Syndrome: Mechanistic Links to Chronic Kidney Disease. Clin. J. Am. Soc. Nephrol.2007; 2: 550-62.

2. Wang, Z. Inflammation, a Link between Obesity and Cardiovascular Disease. Hindawi Publishing Corporation. 2010; 20: 1-17.

3. Jobs $E$, Ingelsson $E$, Riserus $U$, Nerpin $E$, Jons $M$, Sundströmm $\mathrm{K}$, et al. Association Between Serum Cathepsin S and Mortality in Older Adults. JAMA. 2011; 306 : E1-E9.

4. Fei-fei, G LÜ, Shu-zheng, Yun-dai C, Yu-jie Z, Xian-tao S, et al. Relationship between Plasma Cathepsin $\mathrm{S}$ and Cystatin C Levels and Coronary Plaque Morphology of Mild to Moderate Lesions: an In Vivo Study Using Intravascular Ultrasound. Chin. Med. J. (Engl). 2009; 122: 2820-26.

5. Shi GP, Sukhova GK, Grubb A, Ducharme A, Rhode LH, Lee RT, et al. Cystatin $\mathrm{C}$ deficiency in human atherosclerosis and aortic aneurysms. J Clin Invest. 1999; 104: 1191-7.

6. Kim EH, Yu JH, Lee SA, Kim EY, Kim WG, Lee SH, et al. Lack of Association between Serum Cystatin C Levels and Coronary Artery Disease in Diabetic Patients. Korean Diabetes J. 2010; 34: 95-100

7. Hotamisligil GS. Inflammation and metabolic disorders. Nature. 2006; 444: 860-7

8. Korolenko TA, Cherkanova MS, Gashenko EA, Johnston TP, and Brave IY. Cystatin C, Aterosclerosis and Lipid Lowering Therapy by Statins. In : Cystatin : Protease Inhibitor. Nova Science Publisher. USA. 2011. p.187-203. 
9. Zhang H, Cui J, and Zhang C. Emerging Role of Adipokines .As Mediators in Atherosclerosis. World J. Cardiol. 2010; 26: 370-6.

10. Bengtsson E, Hákansson K, Grubb A, and Brånén L. Lack of The Cysteine Protease Inhibitor Cystatin C Promotes Atherosclerosis in Apolipoprotein E - Deficient Mice. Arterioscler. Thromb. Vasc. Biol. 2005; 25: 2151-6.

11. Liu J, Galina K, Sukhova, Jiu-Song, Sun, Wei-Hua, Xu, Libby $\mathrm{P}$, and Guo-Ping, Shi. Lysosomal Cysteine Proteases in Atherosclerosis. Arterioscler. Thromb. Vasc. Biol. 2004; 24: 1359-66.

12. Ärnlőv J. Cathepsin S as A Biomarker : Where Are We Now and What Are The Future Challenges? Biomarkers Med. 2012; 6: 9-11.

13. George SJ, and Johnson J. Atherosclerosis. Molecular and Cellular Mechanism. Wiley Blackwell publisher. WILEYVCH Verlag GmbH \& Co.KGaA, Weinheim. Germany. 2010.173-85.

14. Shlipak MG, Katz R, Cushman M, Sarnak MJ, Stehman-Breen C, Psaty BM, et al. Cystatin C and inflammatory markers in the ambulatory elderly. Am J Med. 2005; 118: 1416.

15. Taglieri N, Koenig W, and Kaski CJ. Cystatin C and Cardiovascular Risk. Clin. Chem. 2009; 55: 1932-43.

16. Sukhova GK, Wang B, Libby P, Pan JH, Zhang Y, Grubb A, et al. Cystatin C Deficiency Increases Elastic Lamina Degradation and Aortic Dilatation in Apolipoprotein E-Null Mice. Circ. Res 2005; 96: 368-75.

17. Urbonaviciene G, Shi GP, Urbonavicius S, Henneberg EW, Lindholt JS. Higher Cystatin C level predicts long-term mortality in patients with peripheral arterial disease. Atherosclerosis $2011 ; 216$ : 440-5.
18. Ferraro S, Marano G, Biganzoli EM, Boracchi P, and Bongo AS. Prognostic Value of Cystatin $C$ in Acute Coronary Syndromes: Enhancer of Atherosclerosis and Promising Therapeutic Target. Clin Chem. Lab. Med. 2011; 49: 13971404.

19. Tsimikas S. Oxidized Low-Density Lipoprotein Biomarkers in Atherosclerosis. Curr. Atheroscler. Reports. 2006; 8: 5561.

20. McCormick SPA. 2004. Lipoprotein (a): Biology and Clinical Importance. Clin. Biochem. Rev. $25: 69-80$.

21. Heidari B. The importance of C-reactive protein and other inflammatory markers in patients with chronic obstructive pulmonary disease. Caspian J Intern Med 2012; 3: 428-35.

22. Paffen $E$, DeMaat MP. C-reactive protein in atherosclerosis: $A$ causal factor? Cardiovasc Res. 2006; 71: 30-9.

23. Lutgens SP, Cleutjens KB, Daemen MJ, Heeneman S. Cathepsin cysteine proteases in cardiovascular disease. FASEB J. 2007; 21: 3029-41.

24. Taleb S, Cancello R, Poitou C, Rouault C, Sellam P, Levy P, et al. Weight Loss Reduces Adipose Tissue Cathepsin S and Its Circulating Levels in Morbidly Obese Women. J. Clin. Endocrinol. Metab. 2006; 91: 1042-7.

25. Willerson JT, Ridker PM. Inflammation as a cardiovascular risk factor. Circulation. 2004; 109: II2-10.

26. Paffen E, and Moniek PM. C-Reactive Protein in Atherosclerosis: A Causal Factor? Cardiovascular Research 2006; 71: 30-9.

27. Lyon CJ, Law RE, and Hsueh WA. Minireview : Adiposity, Inflammation, and Atherogenesis. Endocrinology 2003; 144: 2195-200. 